\title{
A prospective study of growth and rupture risk of small-to-moderate size ascending aortic aneurysms
}

\author{
Sarah Geisbüsch, MD, ${ }^{a}$ Angelina Stefanovic, ${ }^{a}$ Deborah Schray, ${ }^{a}$ Irina Oyfe, ${ }^{b}$ Hung-Mo Lin, $\mathrm{ScD},{ }^{\mathrm{c}}$ \\ Gabriele Di Luozzo, MD, ${ }^{\mathrm{a}}$ and Randall B. Griepp, $\mathrm{MD}^{\mathrm{a}}$
}

\begin{abstract}
Objective: The natural history of small-to-moderate size ascending aortic aneurysms is poorly understood. To follow these patients better, we have developed a method to objectively and reproducibly measure ascending aortic volume on the basis of gated contrast computed tomography scans.
\end{abstract}

\begin{abstract}
Methods: From 2009 to 2011, 507 patients were referred for management of ascending aortic aneurysms. A total of 232 patients $(46 \%)$ with small-to-moderate size aneurysms who did not have compelling indications for operation had measurement(s) of ascending aortic and total aortic volume; 166 patients had more than 1 scan, allowing measurement of growth. A total of 66 patients admitted to the emergency department without ascending aortic pathology served as a reference group.
\end{abstract}

Results: None of the patients experienced rupture, dissection, or death; 3 patients ultimately underwent operation. Ascending aortic volume and volume/total aortic volume differed for the surveillance and reference groups: $132.8 \pm 39.4 \mathrm{~mL}$ versus $78.0 \pm 24.5 \mathrm{~mL} ; 38.3 \% \pm 7.4 \%$ versus $29.1 \% \pm 3.9 \%$, respectively (both $P<.001$ ). Diameters at the sinotubular junction and mid-ascending aortic were $4.1 \pm 0.6 \mathrm{~cm}$ and $4.4 \pm 0.6 \mathrm{~cm}$, respectively, for the surveillance group and $3.0 \pm 0.4 \mathrm{~cm}$ and $3.2 \pm 0.4 \mathrm{~cm}$, respectively, for controls. The increase in ascending aortic volume was $0.95 \pm 4.5 \mathrm{~mL} / \mathrm{year}$ and $0.73 \% \pm 3.7 \% /$ year $(P=.007$ and .012 , respectively $)$. Analysis of risk factors for ascending aortic growth revealed only the use of antithrombotic medication as possibly significant.

Conclusions: Computed tomography volume measurements provide an objective method for ascertaining aortic size and monitoring expansion. Patients with small-to-moderate ascending aortic aneurysms who are carefully followed and managed appropriately have slow aneurysm growth and a small risk of rupture or dissection. Annual computed tomography screening may not be indicated, and elective resection-absent other surgical indications-is not necessary. The rupture/dissection risk for even larger aneurysms in carefully followed patients may be lower than currently believed. (J Thorac Cardiovasc Surg 2014;147:68-74)

Aortic aneurysm disease is the 15 th most common cause of death in individuals aged more than 65 years. On the basis of a population study from 1980 to 1994 , the incidence of thoracic aortic aneurysms is described as 10.4 per 100,000 person-years, and the frequency of diagnosis is probably now higher, given improved imaging techniques and an aging population. ${ }^{1,2}$ The natural history of thoracic aortic aneurysms is poorly understood. To decide on the appropriate treatment strategy for each individual patient, it is critical to be able to estimate the risk of rupture or acute dissection because rupture and dissection are often lethal, mandating preemptive intervention in high-risk patients. ${ }^{3,4}$

\footnotetext{
From the Department of Cardiothoracic Surgery, ${ }^{a}$ Mount Sinai Medical Center, New York, NY; Department of Radiology, ${ }^{\mathrm{b}}$ Mount Sinai Medical Center, New York, NY; and Department of Health Evidence and Policy, ${ }^{\mathrm{c}}$ Mount Sinai Medical Center, New York, NY.

Disclosures: Authors have nothing to disclose with regard to commercial support.

Read at the 38th Annual Meeting of The Western Thoracic Surgical Association, Maui, Hawaii, June 27-30, 2012.

Received for publication June 20, 2012; revisions received Dec 21, 2012; accepted for publication June 27, 2013; available ahead of print Aug 19, 2013.

Address for reprints: Sarah Geisbüsch, MD, Mount Sinai Medical Center, Department of Cardiothoracic Surgery, One Gustave L. Levy Pl, PO Box 1028, New York, NY 10029 (E-mail: sarahgeisbuesch@hotmail.com).

$0022-5223 / \$ 36.00$

Copyright (c) 2014 by The American Association for Thoracic Surgery http://dx.doi.org/10.1016/j.jtcvs.2013.06.030
}

Aneurysms of the ascending aorta are often indolent and frequently discovered incidentally. ${ }^{1}$ How should we proceed with small-to-moderate size aneurysms of the ascending aorta? Guidelines suggest intervention at a diameter of $5.5 \mathrm{~cm}$ because the risk of rupture of an aneurysm is known to increase dramatically with ascending aortic (AA) size greater than $6 \mathrm{~cm} .{ }^{5,6}$ However, it is important to bear in mind that size and growth are determining factors only in asymptomatic patients: Patients with pain or uncontrolled hypertension and those with connective tissue disease or a family history of dissection are at high risk and need to be treated differently. 5,7

Early reports of growth rates have concluded that thoracic aortic aneurysms usually grow slowly, ${ }^{8-12}$ and it has been assumed that more rapid growth puts the patient at increased risk even when the usual diameter thresholds for operation have not been reached. But growth needs to be monitored, and to be reliable, measurements must be performed in an accurate, reproducible manner. Imaging techniques include echocardiography (transthoracic and transesophageal), computed tomography (CT), magnetic resonance imaging, and angiography. ${ }^{6}$ Each one illustrates the aorta in a different way, allowing assessment of size and shape. At the same time, each imaging technique has 


\section{Abbreviations and Acronyms \\ $\mathrm{AA}=$ ascending aortic \\ $\mathrm{CT}=$ computed tomography \\ $\mathrm{SD}=$ standard deviation \\ $\mathrm{SE}=$ standard error}

disadvantages that may mislead one in evaluating the size of the aorta. Furthermore, measurements using different imaging techniques are often hard to compare with one another.

It is important to understand the natural history of thoracic aneurysms, especially in the AA, to intervene before a fatal complication occurs. To avoid being too aggressive in cases in which an aneurysm is unlikely to rupture or dissect, we must develop a reliable method to evaluate size and serially monitor growth. We have frequently observed that reported size changes in AA aneurysms, usually increases, are due to measurements taken at different levels or angles in serial studies. The ideal technique for measuring the aorta would remove as much subjectivity as possible. Because of the methodological problems involved in consistently measuring diameters, as well as the conceptual inadequacy of describing a complex 3-dimensional structure with a single linear measurement, we developed a more objective means of quantifying AA size using volume measurements. We believe that this technique adds to the reliability of CT scan estimation of size and growth, especially when comparison with earlier imaging studies is difficult or impossible.

\section{MATERIALS AND METHODS}

From 2009 to 2011, 232 patients (167 male, 65 female) were referred for management of AA aneurysms and advised to continue surveillance rather than undergo operation. Aneurysms of small-to-moderate size, in the absence of operative indications such as pain, a family history of aneurysm with rupture or dissection, or evidence of recent aneurysm enlargement, or a contraindication to operation such as the presence of other lifethreatening medical conditions, defined the surveillance group. All patients underwent CT scans at the Mount Sinai Medical Center. Volume measurements and measurements of aortic diameters were carried out. Patients were excluded from the study if they had an aneurysm $5 \mathrm{~cm}$ or greater elsewhere in the aorta, an aortic operation before the scans were undertaken, or Marfan syndrome. A total of 66 patients admitted to the emergency department ( 35 male/31 female) without AA pathology who had similar scans served as a reference group. This retrospective analysis, using a review of medical records, was approved by an institutional review board and did not require individual patient consent.

Of the 232 surveillance patients, 166 had more than 1 scan, allowing the calculation of growth rates; 157 patients had 2 scans, and 9 patients had 3 scans. A total of 971 patient-years was monitored. Only scans that were more than 3 months apart were included in the analysis of growth rate. To calculate growth rates, first and last measurements were taken in cases of multiple CT scans. The median (range) time between the first and last scans was $1.1(0.4-4.3)$ years. During the observed interval, 273 other patients underwent elective AA operations at the Mount Sinai Medical Center on initial presentation.

\section{Computed Tomography Measurements}

All measurements and divisions of the aorta into segments were undertaken using Aquarius by TeraTecon, Inc (San Mateo, Calif) and carried out by the same analyst (I.O.). The aorta for each patient was divided into 4 segments: ascending aorta, arch, descending aorta, and abdominal aorta. The volumes of each separate segment were calculated using the dedicated software. Segments were defined as follows: The ascending aorta extends from the root to the proximal origin of the innominate artery, the arch extends between the proximal origins of the innominate and the left subclavian artery, the descending aorta extends from the distal origin of the left subclavian artery to the proximal origin of the celiac axis, and the abdominal aorta extends from the celiac axis to the iliac bifurcation. The planes separating the segments were drawn perpendicular to the central axis of the aorta. The proximal extent of the ascending aorta was obtained by trimming along the aortic valve manually in multiple planes. After the regions of the aorta were segmented, each slice was compared with the source dataset by the analyst to be sure that all areas of interest were covered and correlated with the source data. The ascending aorta as defined by this process is shown in Figure 1.

Because $95 \%$ of the subjects in the surveillance group had only 2 scans, growth rates were estimated by calculating the increase in volume over time between the scans, and extrapolating to obtain a yearly rate. Volumes were analyzed and compared by segment and for the aorta as a whole. For further analysis, the aorta was divided into 2 parts: the ascending aorta and the distal aorta, including the arch and descending and abdominal aortas.

\section{Statistical Analysis}

Data are described as mean \pm standard deviation (SD) and percentage. Wilcoxon, Mann-Whitney, chi-square, and $t$ tests were used to compare differences between groups. Linear regression using the least-squares method was used to describe the relationship between the AA volume and diameter, and the relationship between AA volume growth rate and potential predictors listed in Table 1. For the latter, factors that had a $P$ value less than .2 were further considered in the stepwise multivariate regression analysis. All analyses were performed using SAS software version 9.2 (SAS Institute Inc, Cary, NC).

\section{RESULTS}

Patient Cohort

The mean age at the time of the first scan was $63.6 \pm 12.3$ years in the surveillance group and $57.7 \pm 17.8$ years in the control group $(P=.014)$. Significantly more patients in the surveillance group were male $(35 / 66,53 \%$ of the control vs $167 / 232,72.0 \%$ of the surveillance patients; $P=.004)$ and hypertensive (32/66, 48.5\% in control vs $165 / 200,81.5 \%$, in the surveillance group; information could not be obtained for 32 patients; $P<.001$ ). Body mass index was $29.0 \pm 6.0$ $\mathrm{kg} / \mathrm{m}^{2}$ in controls and $28.5 \pm 4.9 \mathrm{~kg} / \mathrm{m}^{2}$ in the surveillance group $(P=.585)$. Some $31.8 \%$ of control patients $(21 / 66)$ had ever smoked versus $30.8 \%$ of the surveillance group (56/180), with information missing for 52 of the surveillance patients $(P=.916)$. Hyperlipidemia was diagnosed in 21 of 49 control patients $(42.9 \%$ ), whereas 114 of 198 patients $(57.6 \%)$ in the surveillance group had a confirmed history of hyperlipidemia $(P=.064)$. Ten surveillance patients had chronic aortic type B dissection.

\section{Clinical Outcome}

None of the patients experienced rupture, dissection, or death during the interval of surveillance. Three patients in 


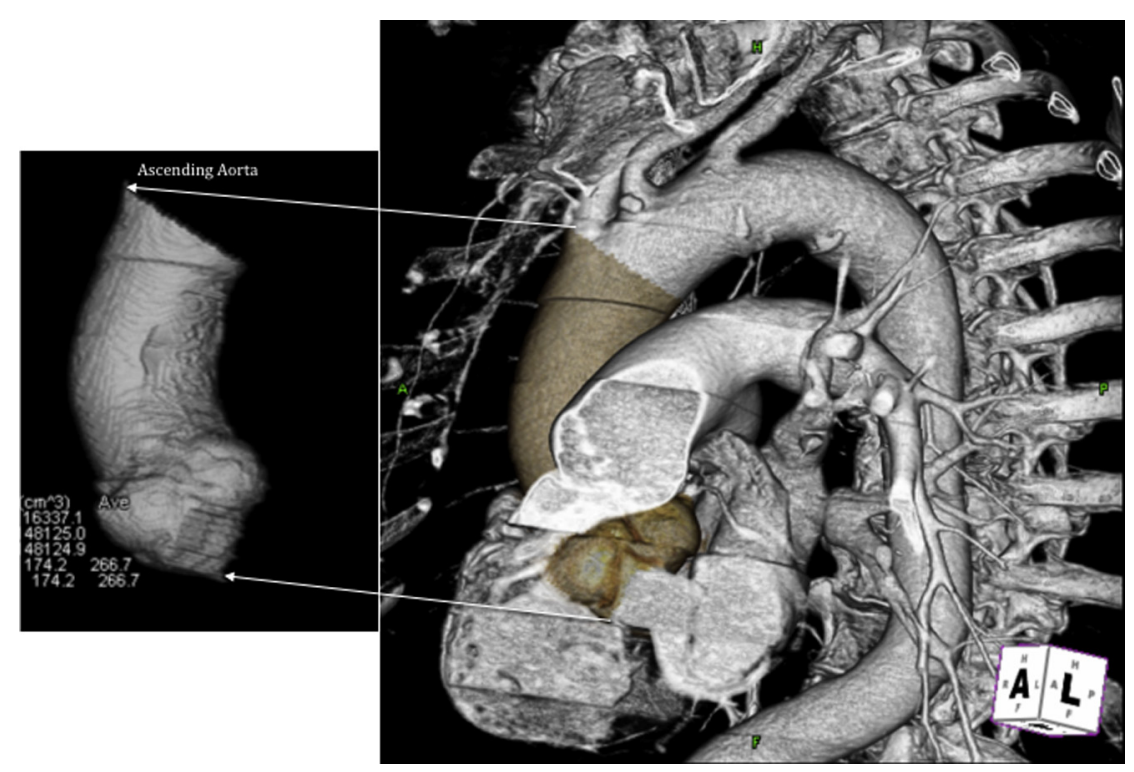

FIGURE 1. Three-dimensional reconstruction of thoracic aorta. The volume measurements we describe rely on construction of planes separating the aorta segments according to a standard protocol, with trimming of the origin of the aorta around the aortic valve. The darkened area highlights the ascending aorta. The defined part of the aorta is extracted from the image, and volume measurements were undertaken using the dedicated software.

the surveillance group ultimately underwent operation. One patient underwent aortic valve and AA replacement because of an increase in the gradient of a stenotic bicuspid aortic valve with concomitant severe regurgitation. The last CT scan, undertaken 1 year before operation, showed an AA volume of $118 \mathrm{~mL}$, with a diameter at the aortic root of $37 \mathrm{~mm}$. Another patient was followed for 4 years for AA dilatation and aortic valve insufficiency before (based

TABLE 1. Possible predictors of ascending aortic growth (milliliters/ year)

\begin{tabular}{lcc}
\hline \multicolumn{1}{c}{ Parameter } & $\begin{array}{c}\text { Frequency (\%) } \\
\text { or mean value }\end{array}$ & $\boldsymbol{P}$ value \\
\hline Age & $64 \mathrm{y}$ & .91 \\
Male sex & 71 & $.08^{*}$ \\
BMI & $29 \mathrm{~kg} / \mathrm{m}^{2}$ & .33 \\
Systolic blood pressure & $122 \mathrm{~mm} \mathrm{Hg}$ & $.19 *$ \\
Family history & 22 & .34 \\
Ever smoked & 31 & .28 \\
History of hypertension & 82 & .67 \\
History of hyperlipidemia & 57 & .46 \\
Bicuspid aortic valve & 20 & .39 \\
Valve pathology & 44 & .69 \\
Dissection & 4 & .75 \\
Antihypertensive medication & 84 & .84 \\
Beta-blocker & 59 & .96 \\
Lipid-lowering medication & 47 & .50 \\
Anticoagulant medication & 56 & $.05 \dagger$ \\
Volume ascending aorta & $133 \mathrm{~mL}$ & .45 \\
Volume of total aorta & $350 \mathrm{~mL}$ & .27 \\
Volume ratio: ascending aorta/total & 38 & .64 \\
\hline
\end{tabular}

$B M I$, Body mass index. *Correlated with increased growth (not significant in multivariate analysis). †Independent predictor of decreased growth (also significant in multivariate analysis). primarily on ventricular size) a Bentall operation was recommended and performed; the volume before the operation was $185 \mathrm{~mL}$, with a diameter of $52 \mathrm{~mm}$. The third patient had aortic valve insufficiency and coronary artery disease in addition to an AA aneurysm.

The patient had been followed for approximately 2 years before developing nonspecific chest pain and dyspnea on exertion, prompting aortic valve repair, AA replacement, and coronary artery bypass grafting. The AA volume before the operation was $151 \mathrm{~mL}$, with a diameter of $46 \mathrm{~mm}$.

\section{Volumes}

The average volume of the entire aorta was $349.7 \pm 90.4$ $\mathrm{mL}$ in surveillance patients, but only $267.1 \pm 72.9 \mathrm{~mL}$ in controls $(P<.001)$. The average volume of the AA was $132.8 \pm 39.4 \mathrm{~mL}$ in the surveillance group and significantly lower in control patients: $78.0 \pm 24.5 \mathrm{~mL}(P<.001)$. The volumes of the distal aorta (arch, descending aorta, and abdominal aorta) were $216.9 \pm 68.2 \mathrm{~mL}$ in surveillance patients and $189.1 \pm 52.8 \mathrm{~mL}$ in controls $(P<.001)$ (Figure 2). The distribution of AA volumes in control and surveillance patients is shown in Figure 3.

\section{Growth Rate}

Only the AA had significant growth: $0.95 \pm 4.5 \mathrm{~mL}$ per year $(P=.007)$ and $0.73 \% \pm 3.7 \%$ per year $(P=.012)$. The remaining distal aorta did not grow within the observed interval: The growth rate was $0.03 \pm 7.0 \mathrm{~mL}$ per year $(P=.962 ; 0.02 \% \pm 3.38 \%$ per year, $P=.947)$. The growth rate for the entire aorta was $0.98 \pm 9.41 \mathrm{~mL}$ per year $(P=.183 ; 0.3 \% \pm 2.85 \%$ per year; $P=.175)$. 


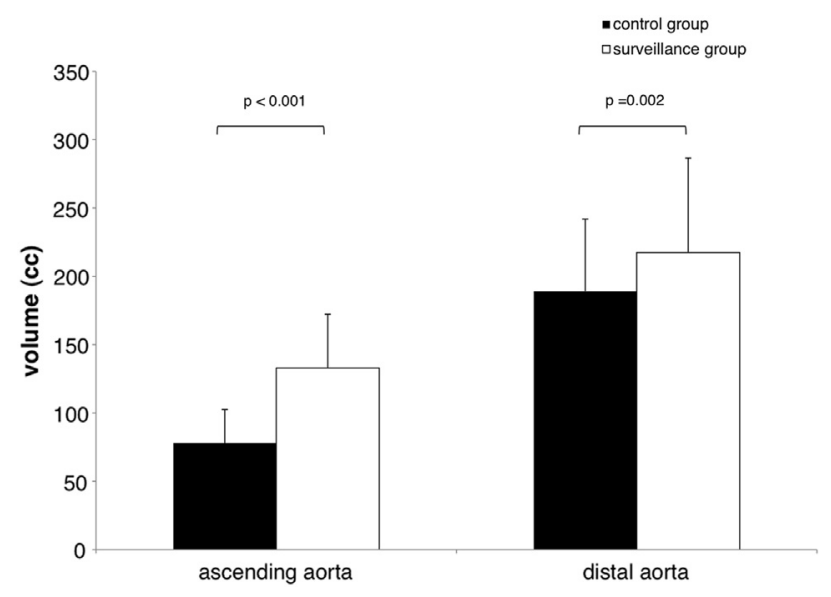

FIGURE 2. Comparison of volumes of ascending and distal aortas. The average volumes of the ascending aorta, distal aorta, and entire aorta are $132.8 \pm 39.4 \mathrm{~mL}, 216.9 \pm 68.2 \mathrm{~mL}$, and $349.7 \pm 90.4 \mathrm{~mL}$, respectively, for surveillance group and $78 \pm 24.5 \mathrm{~mL}, 189.1 \pm 52.8 \mathrm{~mL}$, and 267.1 $\pm 72.9 \mathrm{~mL}$, respectively, for control group. A significant difference was found between the 2 groups for all 3 volumes.

\section{Volume Ratio}

To incorporate the length of the aorta in our analysis of volumes and to allow correction for patient size, we analyzed the ratio of the volume of the AA to the volume of the entire aorta. The ratio was on average $10 \%$ lower in control patients: $38.3 \% \pm 7.4 \%$ in the surveillance group and $29.1 \% \pm 4.0 \%$ in controls $(P<.001)$. The distribution of volume ratios for control and surveillance patients is shown in Figure 4.

\section{Diameter/Volume Comparisons}

A plot of AA diameter at the right pulmonary artery in relation to the AA volume in each scan of patients in the

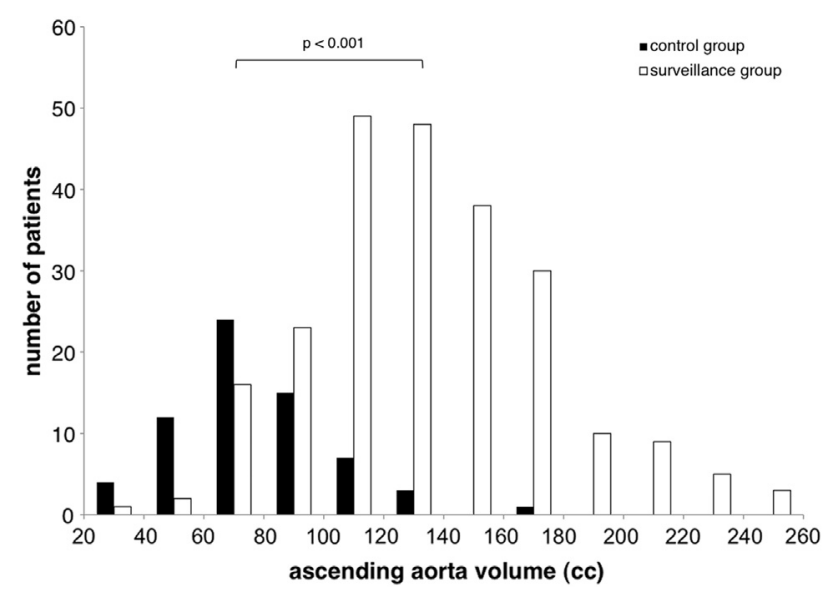

FIGURE 3. Distribution of AA volumes in surveillance and control groups. Patients in the surveillance group had significantly higher volumes $(P<.001)$ : The average was $132.8 \pm 39.4 \mathrm{~mL}$ in surveillance group and 78 $\pm 25 \mathrm{~mL}$ in control group. Volumes tended to be higher with increasing age in both groups.

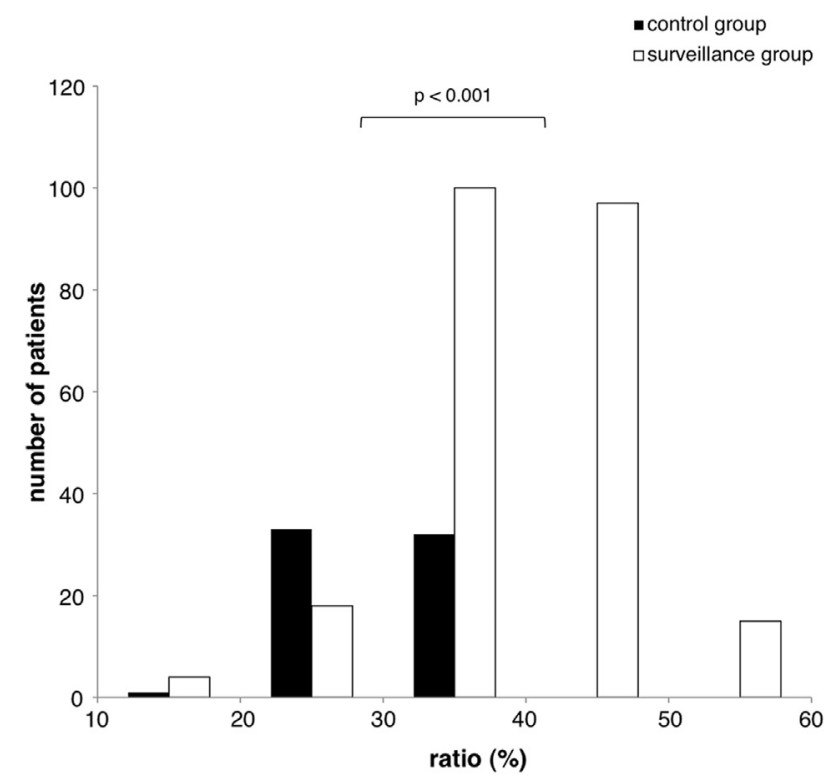

FIGURE 4. Ratio of AA volume compared with total aortic volume. The ratio was approximately $10 \%$ lower in the control group, with an average of $29.1 \% \pm 3.9 \%$ compared with $38.3 \% \pm 7.4 \%$ in patients with AA dilatation. The ratio in patients with chronic dissection was lower than the average in the surveillance group and ranged from $12 \%$ to $33 \%$.

surveillance group and in the only scan from each patient in the control group is shown in Figure 5. A quadratic relationship fitted by linear regression using the least-squares method is shown for the average relationship of volume with diameter measured by a radiologist (volume $[\mathrm{mL}]=-7.41[$ standard error $\{\mathrm{SE}\}, 40.24]+11.36[\mathrm{SE}$, 19.0] $\times$ diameter $[\mathrm{cm}]+4.7[\mathrm{SE}, 2.2] \times$ diameter $[\mathrm{cm}] \times$ diameter $[\mathrm{cm}])$. Thus, an aneurysm with a diameter of $5 \mathrm{~cm}$ would have an average volume of $167 \mathrm{~mL}$, and an aneurysm with a diameter of $6 \mathrm{~cm}$ would have a volume of $230 \mathrm{~mL}$. The average diameters of the control and surveillance groups are shown in Table 2 . The average diameter at the right pulmonary artery was $4.4 \pm 0.6 \mathrm{~cm}$ for the surveillance group and $3.2 \pm 0.4 \mathrm{~cm}$ for the control group $(P<.001)$.

\section{Predictors of Growth Rate}

A univariate analysis of gender; age at first scan; body mass index; history of hypertension; history of hyperlipidemia; history of smoking; family history; bicuspid aortic valve; systolic blood pressure; volume of the AA; volume of the entire aorta; ratio of AA/total aorta; antihypertensive, antilipidemic, and anticoagulant medications; intake of beta-blocker; valve pathology including $\mathrm{s} / \mathrm{p}$ aortic valve replacement; and aortic dissection was undertaken. The $P$ value was less than .2 for male gender $(P=.088)$, anticoagulant medication $(P=.053)$, and systolic blood pressure $(P=.188)$; thus, those factors were considered in the stepwise regression. The stepwise regression identified 


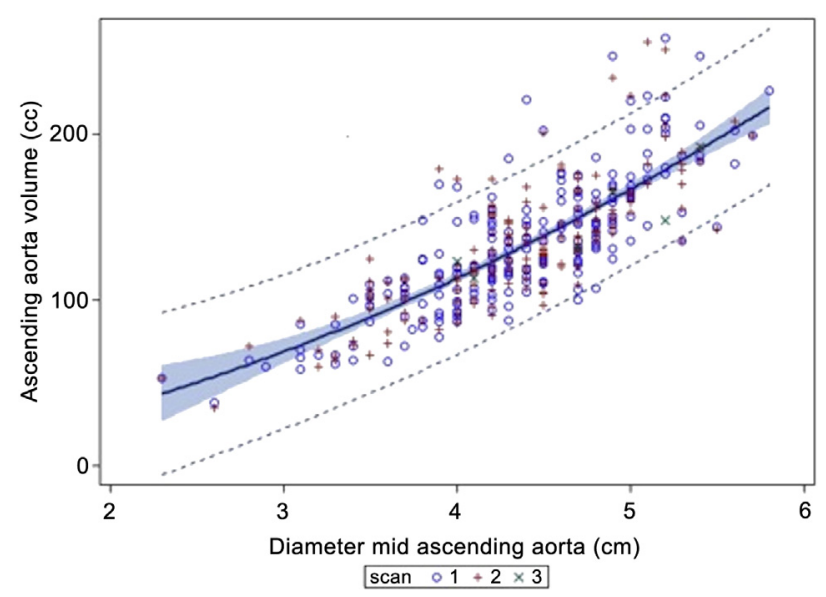

FIGURE 5. The AA diameter at the right pulmonary artery in relation to the AA volume found in each scan of patients in the surveillance group and in the only scan from each patient in the control group. A quadratic relationship fitted by linear regression is shown for the average relationship of volume and diameter. Thus, an aneurysm with a diameter of $5 \mathrm{~cm}$ would have a volume of $167 \mathrm{~mL}$, and an aneurysm with a diameter of $6 \mathrm{~cm}$ would have a volume of $230 \mathrm{~mL}$.

anticoagulant medication as the sole significant predictor of growth rate. Specifically, use of an anticoagulant drug was associated with a decreased growth rate (Table 1). Patients taking low-dose aspirin, warfarin, or clopidogrel were included in this group; most were taking aspirin.

\section{Rupture and Dissection Risk}

The patients in the surveillance group were followed for a total of 971 patient-years. No instance of rupture or dissection occurred, suggesting that the risk of these adverse outcomes is less than $0.1 \%$ per patient-year. However, 3 patients were withdrawn from the study to undergo operation (albeit all for hemodynamic reasons rather than change in the size of the aneurysm). If one argued that all 3 patients would have sustained rupture/dissection if operation had not been performed, the risk would increase only to $0.3 \%$ per patient-year.

\section{DISCUSSION}

Our observations in 232 patients monitored over several years point out that small-to-moderate size AA aneurysms

TABLE 2. Average diameters (centimeters) of the aorta in control and surveillance groups

\begin{tabular}{lcc}
\hline & Surveillance group & Control group \\
\hline Sinotubular junction & $4.1 \pm 0.6$ & $3.0 \pm 0.4$ \\
Mid-ascending aorta & $4.4 \pm 0.6$ & $3.2 \pm 0.4$ \\
Arch & $3.2 \pm 0.5$ & $2.6 \pm 0.3$ \\
Descending aorta & $2.9 \pm 0.5$ & $2.5 \pm 0.3$ \\
Celiac axis & $2.5 \pm 0.4$ & $2.2 \pm 0.3$ \\
Renal arteries & $2.2 \pm 0.3$ & $2.1 \pm 0.3$ \\
Abdominal & $2.1 \pm 0.4$ & $1.8 \pm 0.5$ \\
\hline
\end{tabular}

All $P$ values $<.001$, except for the renal arteries. grow slowly and that the risk of rupture or dissection is low. In our surveillance group of patients, we did not observe a single fatal complication. Because size and growth are independent risk factors for dissection and rupture $^{5,11}$; however, it is important to rely on accurate measurements.

Previous studies of expansion of the thoracic aorta using diameters report growth rates ranging from $0.10 \mathrm{~cm} /$ year to $0.42 \mathrm{~cm} /$ year for the thoracic aorta. ${ }^{8-13}$ Elefteriades and Farkas $^{13}$ report an overall growth rate of $0.12 \mathrm{~cm} /$ year for the thoracic aorta, with the descending aorta growing faster than the AA ( 0.3 vs $0.1 \mathrm{~cm} /$ year). These authors confirm our observation with regard to patients under surveillance: Not a single patient of theirs died of rupture in a group with asymptomatic small aortic aneurysms, less than $5.5 \mathrm{~cm}$ in diameter. Consensus seems to exist that the risk of rupture is low for patients with small thoracic aneurysms.

Coady and colleagues ${ }^{5}$ performed growth rate estimates in 79 patients according to initial aneurysm size. They not only showed that descending aneurysm growth is faster than growth in ascending aneurysms but also addressed the question of whether growth rate is related to size: They found that larger aneurysms at initial presentation grew faster. Although this observation is supported by 2 earlier studies, ${ }^{10,11}$ Coady and colleagues, in their multivariable model, could not identify size as independently affecting overall aneurysm growth rate, and Hirose and colleagues ${ }^{9}$ also did not support the idea that there is a certain threshold of size that influences growth rate.

The growth rate that we measure in this series is an order of magnitude lower than in all these previous studies. A volume increment of $1 \mathrm{~mL} / \mathrm{year}$ translates into an increase in diameter of only $0.02 \mathrm{~cm} /$ year for an AA aneurysm with a length of $8.7 \mathrm{~cm}$, the average estimated length in this series. We are confident that our measurements are accurate, although it is conceivable that there is some as yet unexplained error in our determinations. We suggest that the substantial difficulties in accurately measuring AA diameter described earlier, combined with an understandable unconscious prejudice that growth must be occurring, have resulted in a systematic overestimation of later measurements in aneurysms examined serially. It could also be that the "natural" history of AA aneurysm growth is changing as the result of better medical therapy or selfselection of patients who participate in surveillance. It also should be pointed out that all our measurements were collected prospectively, and consequently did not include a look back at patients who came to medical attention because of rupture/dissection, a possible methodological flaw in some previous studies. Although it is true that the size of the aneurysms in this group is modest, with an average diameter of $4.4 \pm 0.6 \mathrm{~cm}$ at the time of the first scan, neither we nor others have been able to demonstrate an unequivocal influence of size on growth rate. 


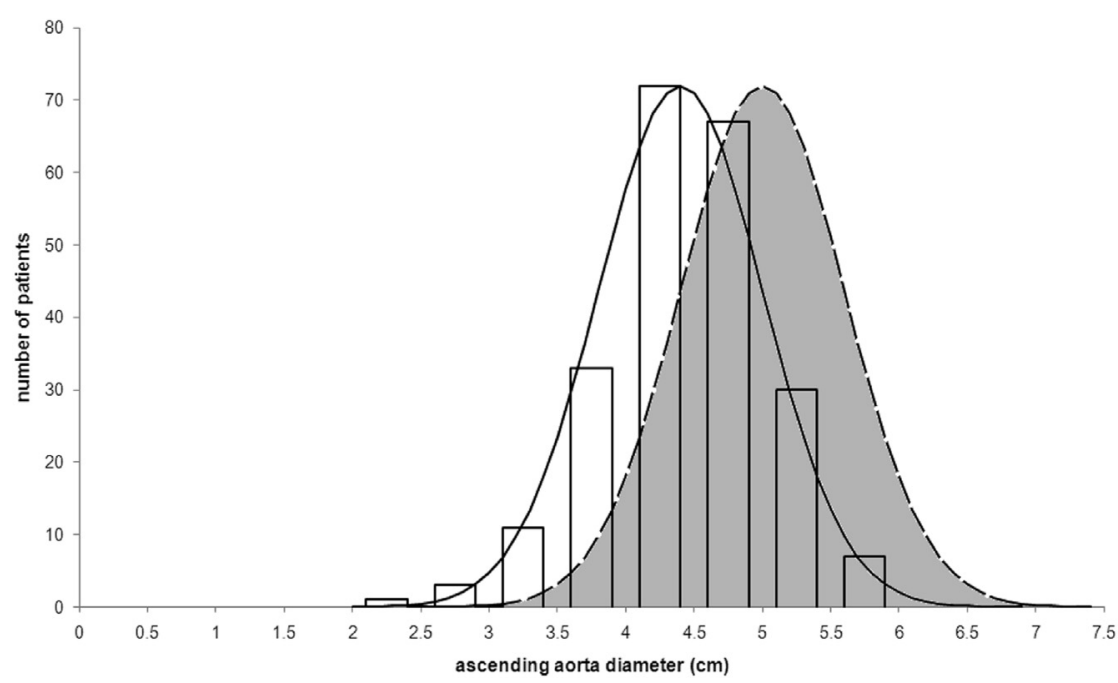

FIGURE 6. We can see a normal distribution of aortic diameters in our patient population under surveillance. Given the small annual risk of rupture $(<0.1 \%-0.3 \%)$, it might be reasonable to suggest that similar patients with larger aneurysms, perhaps $1 \mathrm{SD}$ greater (ie, $5.0+0.6 \mathrm{~cm})$, should be followed closely rather than undergo elective resection.

A possible criticism of using volume to follow aneurysm growth is that diameter may be a better predictor of rupture risk than volume, given the dependency of wall tension on diameter ${ }^{14}$ : We concede that a long slim aorta may be less dangerous than a short fat one of the same volume. We would agree that diameters are important for describing ascending aneurysms, but we would argue that changes in diameter, given the problems cited, are unlikely to detect growth accurately.

We observed a normal distribution of radiologically measured AA diameters in our patient population under surveillance with an estimated mean $\pm \mathrm{SD}$ for the AA diameter of $4.4 \pm 0.6 \mathrm{~cm}$ (Figure 6). Approximately $95 \%$ of the subjects had a diameter less than $5.4 \mathrm{~cm}$. A surprising but encouraging finding of this prospective study is that the rupture/dissection risk of these small-to-moderate size aneurysms is extremely low: less than $0.1 \%$ to $0.3 \%$. This implies that-absent other indications-elective resection is not indicated in this size range. Therefore, it might be reasonable to suggest that a patient population with aneurysms $1 \mathrm{SD}$ larger- $(5.0+0.6 \mathrm{~cm})$ than in this series of surveillance patients-could also be followed closely rather than undergo elective resection. It would also seem that annual scanning is likely not necessary for patients with aneurysms the size of those in the surveillance group. We would suggest that biennial scanning be combined with annual follow-up to measure blood pressure control, $\beta$ blockade, and lifestyle modification, such as smoking cessation.

Finally, an unexpected finding-that anticoagulant therapy seems to inhibit AA growth-is difficult to explain. A Danish study of 148 patients with small-to-moderate size abdominal aortic aneurysms in 2008 also found that low-dose aspirin was associated with decreased growth. They considered the possibility that a change in lifestyle in users of low-dose aspirin occurs, which prevents progression of disease. ${ }^{15}$ One could also invoke inhibition of microthrombus formation in the intima in low-flow regions of the aneurysm - with secondary inflammation - as a possible explanation for why anticoagulants retard aneurysm expansion. A confirmation of the correlation of anticoagulant use with slower aneurysm growth in a prospective randomized study would be appropriate before any change in therapeutic recommendations.

\section{CONCLUSIONS}

$\mathrm{CT}$ volume measurements of the aorta provide an objective method of ascertaining aortic size and monitoring expansion. Small-to-moderate size AA aneurysms in patients who are carefully followed and managed appropriately, including the use of antihypertensive medications and beta-blocking agents, have a slow rate of growth and a small risk of rupture and dissection. Annual CT scanning may not be required in this population, and elective resection, absent other surgical indications, is unnecessary. It may be appropriate to consider surveillance and medical management of patients with AA aneurysms somewhat larger than those reported in this series.

\section{References}

1. Clouse WD, Hallett JW Jr, Schaff HV, Gayari MM, Ilstrup DM, Melton LJ III. Improved prognosis of thoracic aortic aneurysms: a population-based study. JAMA. 1998;280:1926-9.

2. Ramanath VS, Oh JK, Sundt TM III, Eagle KA. Acute aortic syndromes and thoracic aortic aneurysm. Mayo Clin Proc. 2009;84:465-81.

3. Golledge J, Eagle KA. Acute aortic dissection. Lancet. 2008;372:55-66.

4. Rizzo JA, Coady MA, Elefteriades JA. Procedures for estimating growth rates in thoracic aortic aneurysms. J Clin Epidemiol. 1998;51:747-54. 
5. Coady MA, Rizzo JA, Hammond GL, Mandapati D, Darr U, Kopf GS, et al. What is the appropriate size criterion for resection of thoracic aortic aneurysms? J Thorac Cardiovasc Surg. 1997;113:476-91.

6. Hiratzka LF, Bakris GL, Beckman JA, Bersin RM, Carr VF, Casey DE Jr, et al. 2010 ACCF/AHA/AATS/ACR/ASA/SCA/SCAI/SIR/STS/SVM Guidelines for the diagnosis and management of patients with thoracic aortic disease. A Report of the American College of Cardiology Foundation/American Heart Association Task Force on Practice Guidelines, American Association for Thoracic Surgery, American College of Radiology, American Stroke Association, Society of Cardiovascular Anesthesiologists, Society for Cardiovascular Angiography and Interventions, Society of Interventional Radiology, Society of Thoracic Surgeons, and Society for Vascular Medicine. J Am Coll Cardiol. 2010;55: e27-129.

7. Koullias GJ, Ravichandran P, Korkolis DP, Rimm DL, Elefteriades JA. Increased tissue microarray matrix metalloproteinase expression favors proteolysis in thoracic aortic aneurysms and dissections. Ann Thorac Surg. 2004;78:2106-11.

8. Coady MA, Rizzo JA, Hammond GL, Kopf GS, Elefteriades JA. Surgical intervention criteria for thoracic aortic aneurysms: a study of growth rates and complications. Ann Thorac Surg. 1999;67:1922-6; discussion 53-8.

9. Hirose $Y$, Hamada $S$, Takamiya $M$, Imakita $S$, Naito $H$, Nishimura $T$ Aortic aneurysms: growth rates measured with CT. Radiology. 1992;185: 249-52.

10. Masuda Y, Takanashi K, Takasu J, Morooka N, Inagaki Y. Expansion rate of thoracic aortic aneurysms and influencing factors. Chest. 1992;102:461-6.

11. Dapunt OE, Galla JD, Sadeghi AM, Lansman SL, Mezrow CK, de Asla RA, et al. The natural history of thoracic aortic aneurysms. J Thorac Cardiovasc Surg. 1994;107:1323-33

12. Rizzo JA, Darr U, Fischer M, Johnson KM, Finkle JK, Gusberg RJ, et al. Multimodality serial follow-up of thoracic aortic aneurysms. Int J Angiol. 1997;6: 153-6.

13. Elefteriades JA, Farkas EA. Thoracic aortic aneurysm clinically pertinent controversies and uncertainties. J Am Coll Cardiol. 2010;55:841-57.

14. Li JK. Comparative cardiac mechanics: Laplace's Law. J Theor Biol. 1986;118: 339-43.

15. Lindholt JS, Sorensen HT, Michel JB, Thomsen HF, Henneberg EW. Low-dose aspirin may prevent growth and later surgical repair of medium-sized abdominal aortic aneurysms. Vasc Endovasc Surg. 2008;42:329-34.

\section{Discussion}

Dr Michael Fischbein (Stanford, Calif). Dr Griepp and his research laboratory have been leaders in thoracic aortic surgery and contributed so much both clinically and scientifically.

I have 3 questions. First, any given increase in the AA volume can be secondary to (1) an increase in the maximum dimension or (2) elongation of the aorta with no change in the maximum dimension. Do you think these 2 situations have the same risk of rupture?

Dr Geisbuesch. No. We do not think the risk of rupture is the same. We know that wall tension increases with increased diameter, so we believe that a short, fat aorta is more likely to rupture than a long slim one.

Dr Fischbein. Second, tell us how you are using aortic volume measurements at Mount Sinai. Are you using a combination of both maximum dimension and volume change, and what exact volume change or rate of volume change are you using to determine if someone should then proceed to surgery?

Dr Geisbuesch. The decision whether or not to operate on a patient can of course never be based on a single measurement, so at Mount Sinai we look at family history of rupture or dissection and other risk factors, as well as volume measurements in combination with maximum dimension. In addition, we can look at the ratio of AA volume to total aortic volume. If we see a significant increase in volume in combination with an increase in maximum diameter, depending on these other factors, this would then lead to the decision to a short follow-up or to operate on the patient electively.

The advantage of the volume measurement in this context is that because it is an objective, reproducible measurement, it reliably ascertains whether a change has really occurred and can pinpoint the location of an enlargement, if present. In the event that no change in volume is documented, we can be more confident than with diameter measurements in reassuring the patient that no growth has occurred, and that surgery is not needed.

Dr Fischbein. Third, can this program measuring volume change be easily used universally? Can everyone adopt this new format?

Dr Geisbuesch. Yes. We are convinced that volume measurements can be performed at other institutions. As with every new technique, there is certainly a learning curve to obtain accurate measurements and achieve reliability, but from our experience we can only say that if the technician goes back and repeats the measurements, he/she gets the same results. The key to this is consistency in how the CT scans are performed and the measurements are undertaken. Once consistency has been achieved, I think CT volume measurements are far more objective and reproducible than measurements of diameter at a single level. 